\title{
RAZLIČNE SCENSKE POSTAVITVE CANKARJEVIH DEL V LUUBLANSKI DRAMI IN DRUGIH SLOVENSKIH GLEDALIŠČIH MED OBEMA VOJNAMA (1918-1941)
}

Ključne besede: scenografija, dramatika, Ivan Cankar, umetnost med obema vojnama, scenografija med obema vojnama, ekspresionizem, nova stvarnost, avantgarda

Med deli slovenskih dramatikov, ki so jih uprizorili v slovenskih gledališčih med obema vojnama, so bila gotovo najbolj pogosto uprizorjena dela Ivana Cankarja. Cankar je umrl dober mesec dni po koncu prve svetovne vojne, njegova dela pa so ravno z letom 1918 postala zvezda stalnica repertoarjev slovenskih gledališč.

V razpravi bom skušala podrobneje razložiti in utemeljiti različne scenske postavitve Cankarjevih del na naših odrih med obema vojnama. V tem obdobju so namreč skušali večinoma simbolistično obarvana Cankarjeva dela na odru prvič postaviti s popolnoma novo likovno (scensko) podobo oziroma jih prevesti v ekspresionistično in avantgardno scensko govorico, značilno za sočasno likovno umetnost. Za slovensko likovno umetnost časa med obema vojnama so značilni številni slogi, od ekspresionizma in nove stvarnosti pa vse do prvih avantgard in surrealizma. Zato sem želela ugotoviti, kateri izmed teh slogov so se kazali v scenskih postavitvah na naših odrskih deskah in seveda kdaj oziroma s kolikšnim zamikom za razvojem slovenske likovne umetnosti se je to zgodilo.

V letih med 1918 in 1941 so v ljubljanski Drami Cankarjeva dela uprizorili kar devetnajstkrat, v mariborski sedemnajstkrat in v Slovenskem gledališču v Trstu sedemkrat. Največkrat uprizorjeno delo so bili Hlapci (desetkrat), Kralj na Betajnovi (devetkrat) in Za narodov blagor (devetkrat). 
Po številčnosti uprizoritev pa bi jih lahko primerjali z uprizoritvami Shakespearovih del. ${ }^{1}$

Shakespeara so v naših gledališčih igrali skoraj vsako sezono, dela Ivana Cankarja pa so prihajala na spored ob vseh večjih slovesnostih. $Z$ uprizoritvijo Jakoba Rude (12. 5. 1926, režija: M. Skrbinšek, SNG Drama Ljubljana) so leta 1926 na primer počastili 50-letnico Cankarjevega rojstva. Z njegovimi deli so počastili tudi vse okrogle obletnice ustanovitve povojnega gledališča v Ljubljani. Z uprizoritvijo Za narodov blagor pa so po drugi svetovni vojni, 16. oktobra 1945, slavnostno odprli vrata Ljubljanske Drame, prvič v novi, osvobojeni Jugoslaviji.

Cankarjeva dela so naša gledališča rada uprizarjala tudi na gostovanjih po drugih jugoslovanskih odrih. Tako je na primer ljubljanska Drama že na svojem prvem gostovanju v julijskih dneh 1920. leta v Zagrebu na kongresu jugoslovanskih igralcev uprizorila Cankarjevo Pohujšanje $v$ dolini šentflorjanski in ponovila obisk v oktobru, ko je slavil Zagreb petindvajsetletnico dograditve novega gledališča.

Pa tudi sicer so slovenski režiserji skrbeli, da so bila Cankarjeva dela čim večkrat na sporedu. Tako je na primer režiser Milan Skrbinšek na odru Slovenskega gledališča v Trstu v sezoni 1918/1919 v ciklu Cankarjevih večerov uprizoril skoraj vsa njegova dela, razen Jakoba Rude in Romantičnih duš. Med njimi so bili krstno uprizorjeni Hlapci.

Tudi v ljubljanski Drami so bile med letoma 1920 in 1926 na novo uprizorjene vse Cankarjeve drame in komedije $\mathrm{z}$ edino izjemo Lepe Vide (čeprav je bila nastavljena $\mathrm{v}$ repertoarnih načrtih). Krstno predstavo pa so doživele Romantične duše. Delo pri novi interpretaciji Cankarja sta si v tem času delila režiserja Osip Šest in Milan Skrbinšek.

Večinoma so Cankarjeva dela uprizarjali režiserji (najpogosteje Milan Skrbinšek in Ciril Debevec), ki so bili znani po tem, da so dajali prednost notranji režiji, torej simboliki, pomenu in učinku besedila samega. K zunanji režiji so se zatekli le tedaj, ko je bila ta nujna za simbolično dopolnitev Cankarjevega besedila. Tako so bile scensko najbolj zanimive uprizoritve Pohujšanja v dolini šentflorjanski.

1 Angleški dramatik je namreč zaradi številčnosti uprizorjenih del in priljubljenosti med občinstvom dobil vzdevek »naš« Shakespeare. 
Razvoj scene pri uprizoritvah Cankarjevih del je bolj sledil razvoju scenografije v slovenskih gledališčih. Tako lahko tudi pri teh scenografijah govorimo o kulisnih postavitvah, ekspresionističnih in nadrealističnih elementih ter o prvih avantgardnih scenskih poskusih (predvsem na ljudskih in delavskih odrih). Delno so verjetno na odrsko opremo pri uprizoritvah vplivale Cankarjeve opombe v didaskalijah, nekaj pa je prispevalo tudi stalno pomanjkanje denarja za nove scenografije in seveda navajenost občinstva na točno določene principe scenskih postavitev Cankarjevih del. Hkrati je na uprizoritve vplivala cenzura, saj je cenzurni svet vedno znova natančno in skrbno preučil prav politično sporne dele $\mathrm{v}$ njih, kar je včasih povzročilo črtanje več prizorov. ${ }^{2}$

Kljub vsem težavam (tehničnim, finančnim in cenzurnim), ki jih je slovensko gledališče v tem času imelo, pa so na odrih le nastajale scenografije, ki so bile primerljive s sočasnimi na evropskih. Prva znamenita scenska postavitev, s katero je ljubljansko gledališče ujelo dogajanje na evropskih odrih ter celo prehitelo razvoj v slovenski likovni umetnosti, je bila konstruktivistično zasnovana kulisna scena za Čapkovo delo R. U. R. (4. 10. 1922, režija: O. Šest, scenografija: V. Skrušny, SNG Drama Ljubljana). ${ }^{3}$ Tej sta sledili bolj ali manj z ekspresionističnimi in novostvarnostnimi elementi postavljeni sceni za Langerjevo Periferijo (7. 10. 1925, režija: O. Šest, scenografija: V. Skrušny, SNG Drama Ljubljana) in Cankarjevo Pohujšanje v dolini šentflorjanski (26. 9. 1928, režija: M. Skrbinšek, scenografija: V. Skrušny ml., SNG Drama Ljubljana). Po novih scenskih zamislih sta izstopali Cerkvenikova Roka pravice (12. 4. 1928, režija: M. Skrbinšek, scenografija: I. Vavpotič, SNG Drama Ljubljana) in Frondijeva Bitka (28. 4. 1929, režija:

2 Cenzura tekstov je sprva potekala po strogih cenzurnih merilih, ki jih je postavila rajnka Avstro-Ogrska leta 1850 (zakon št. 454). O tem glej Mahnič, M., Iz arhiva. Zgodovina gledališke cenzure na Slovenskem, GLLjD 1949-1950, 10, str. 204. Leta 1938 pa so se strogim avstro-ogrskim cenzurnim zapovedim pridružile še nove strožje jugoslovanske. Tako je sredi leta 1938 imenovani gledališki cenzurni svet na primer razpravljal tudi o besedilu Cankarjevih »Hlapcev« (2. 2. 1939, režija: C. Debevec, SNG Drama Ljubljana). O tem glej: Kocjančič, A., Scenografija v slovenskih dramskih gledališčih med obema vojnama (1918-1941), Ljubljana 2005 (magistrsko delo, Oddelek za umetnostno zgodovino, Filozofska fakulteta, Univerza v Ljubljani, tipkopis).

3 Scena te predstave je skoraj za dve leti prehitela slovensko likovno dogajanje. V tem času je namreč v slovenski likovni umetnosti doživljal svoj vrh ekspresionizem. Konstruktivizem pa je k nam prinesel šele Avgust Černigoj po letu 1924. 
C. Debevec, scenografija: I. Vavpotič, SNG Drama Ljubljana). Prva je slovela po ekspresionistični sceni s posameznimi nadrealističnimi elementi, druga pa po konstruktivistično oblikovanem ogrodju podmornice Nikko. Njeno ogrodje je bilo še vedno oblikovano iz kulis. ${ }^{4}$

Velik korak naprej je razvoj slovenskega gledališča in tudi scenskega oblikovanja doživel z gostovanji hrvaškega režiserja Branka Gavelle. Z odrskim prostorom se je dobesedno igral in ga prilagajal besedilu, pa tudi igralcem. Scenografijo je imenoval »odrska arhitektura« (Gavella, 1968, 169). Tako sta pri Balzacovem Mercadetu (28. 12. 1930, režija: B. Gavella, scenografija: V. Uljaniščev, SNG Drama Ljubljana) skupaj s scenografom Vasilijem Uljaniščevim postavila simultano sceno. Na oder sta postavila narobe obrnjene kulise, tako da so bile te s svojo zadnjo stranjo in podpornimi palicami obrnjene proti gledalcem. Za slovenske gledališke razmere zelo izvirno scensko postavitev pa je imela tudi Gavellova postavitev Shakespearove komedije Kar hočete (27. 3. 1932, režija: B. Gavella, scenografija: L. Babić, SNG Drama Ljubljana). Skupaj z zagrebškim scenografom Ljubom Babićem sta namreč na oder postavila razpolovljen valj in $\mathrm{z}$ njim dobila popolnoma abstraktno sceno. ${ }^{5}$ Razen valja in igralcev pa je bil oder prazen. Obe strani prerezanega valja sta imeli tudi svojo barvo. Konkavna stran ploskve je bila žolta, konveksna pa vijoličasta. ${ }^{6}$ Oba lika je osvetljevala močna luč. ${ }^{7}$ Glavna novost je bila v tem, da je bil igralec tisti, ki je s svojo igro premikal in spreminjal sceno, hkrati pa je scena določala igralčev položaj. ${ }^{8}$ Prvič v našem gledališču sploh je šlo za sožitje igralca in scene. Scena je bila podrejena igralcu in igralec je bil tisti, ki je sceno dobesedno prijel v

4 Glej Kocjančič 2005, cit. op. 2.

5 Svojo scensko postavitev je za »abstraktno« označil tudi Gavella; B.G. (Gavella, B.), O režiji Shakespear-ove komedije Kar hočete, GLLjD 1931-1932, 15, str. 1.

6 Kozak, J., Gavellov Shakespeare, Jutro, 31. 3. 1932.

7 Žal se je večina podatkov o scenski postavitvi ohranila le v pisnih virih. V Slovenskem gledališkem muzeju se je namreč ohranila le ena fotografija z Miro Danilovo ter znamenitim valjem. O tem: Moravec, D., Sprehod po razstavi, Dokumenti SGM 2 (1964), str. 60.

8 Gavella 1931-1932, cit. op. 5, str. 1: "Izhodišče za vso zamisel je bila scena, ko čita Malvolio pismo. V realistični sceneriji bi se morali prisluškovalci skrivati za kakim grmom in Malvolijevo premikanje bi bilo precej ovirano, ker bi moral biti vedno v neposredni bližini tistega grma zato, da bi ga lahko prisluškovalci razumeli. Jaz sem napravil ravno nasprotno. Pri meni se tako rekoč "grm « premika za Malvolijem." 
svoje roke. Scenograf in režiser sta dala le idejo. Na končni videz scene pa so vplivali igralci.

Vplive funkcionalistične arhitekture je na ljubljanske odrske deske zanesel arhitekt Ivo Spinčič s postavitvijo scenografije za Kulundžićevo Polnoč (19. 10. 1927, režija: C. Debevec, scenografija: I. Spinčič, SNG Drama Ljubljana). To smer je skušal v scenografiji nadaljevati arhitekt Ernest Franz. Najbolje je svojo namero izpeljal v scenografiji za Shakespearovo ljubezensko tragedijo Romeo in Julija (21. 9. 1940, režija: B. Kreft, scenografija: E. Franz, SNG Drama Ljubljana).

Vplive avantgardnih gledališč, predvsem gledališke delavnice v Bauhausu, je v ljubljansko Dramo zanesel Bojan Stupica. Tako pri scenski postavitvi Shawovega dela Kako zabogatiš (9. 11. 1935, režija in scenografija: B. Stupica, SNG Drama Ljubljana) kot tudi pri Kaufmann-Ferberjevi Simfoniji 1937 (11. 2. 1937, režija in scenografija: B. Stupica, SNG Drama Ljubljana) se je pri izbiri odrske opreme naslonil na bauhausovske izume ter uporabil notranjo opremo Marcela Breuerja. ${ }^{9}$

K našemu scenskemu razvoju so $\mathrm{v}$ poznejši letih (po letu 1926) pomembno prispevale tudi nekatere scenske postavitve Cankarjevih del. Sprva so bila tudi Cankarjeva dela uprizorjena s kulisami, postavljena $\mathrm{v}$ prostor »italijanske škatle« oziroma v tako imenovani "plahutajoči sceni» (Jerman, 1982, 117). ${ }^{10} \mathrm{~V}$ tak tip odrskega prostora so scenografi vedno znova postavljali Kralja na Betajnovi. Ker ima Kralj na Betajnovi le eno prizorišče, to je notranjost krčme, ki pa za sam potek igre in simboliko besedila ni bistveno, verjetno kulisne stene poteka predstave niso motile. Samo v ljubljanski Drami so v času med obema vojnama delo uprizorili štirikrat, in sicer vsakič v novi režiji.

Prvo predstavo je režiral Anton Cerar - Danilo (17. 12. 1918, režija: A. Cerar Danilo, SNG Drama Ljubljana). To je bila hkrati tudi prva povojna uprizoritev Cankarjevih dramskih del na ljubljanskem odru. Žal se sli-

9 Vplive Bauhausa sta kazali tudi dve operni scenografiji, in sicer za: Delannoyev balet "Damski lovec" (1931, scenografija: V. Uljaniščev) in za Weillovo opero "Car se da fotografirati« (1931, režija: B. Kreft, scenografija: V. Uljaniščev).

10 Scensko postavitev je poimenoval z izrazom »plahutajoča «, ker so viseči platneni prospekti vzvalovili, če se jim je igralec preveč približal. 
kovno gradivo (fotografije, scenski osnutki) ni ohranilo. Sklepamo pa, da je bila predstava, tako kot tudi vse druge v prvi povojni gledališki sezoni (1918/1919), postavljena na t. i. »plahutajoči sceni«, v prostoru »italijanske škatle«. Igralna ploskev pa so bila kar odrska tla oziroma točka nič.

Ker vso prvo gledališko sezono ljubljanska Drama ni imela scenografa, ${ }^{11}$ so sceno postavljali kar režiserji sami (večino predstav te sezone je uprizoril režiser Hinko Nučič). Pomagali so si predvsem s t. i. »fundusom», neke vrste albumom z vzorci gledaliških kulis, ki jih je naše gledališko vodstvo pred prvo svetovno vojno kupovalo na Dunaju. Album je naslikal predvojni gledališki mojster Alojz Waldstein. Kljub temu da so med vojno kar nekaj kulis napadle in uničile vlaga in miši, pa se jih je po Nučičevem pričevanju vendarle veliko tudi ohranilo. V albumu so bile zapisane: „Kmetiška soba - viseči prospekt $z$ vrati na sredini, 4 polne kulise, 2 ozki kulisi, 1 kulisa z oknom, ki se odpira, dvoje vrat; pa Salon A, Salon B, Salon C, Rokoko soba, Bidermajer soba, Viteška dvorana, Angleška dvorana, Ječa $z$ oboki, Gozd, prospekt, Park, prospekt, Vrt, prospekt, Vas, prospekt, 6 gozdnatih kulis, Kraljevska dvorana itd., pa razni »versatzstücki«, kapelice, grmovja, skale, pečine in drugo" (Nučič, 1960, 98). Režiserji so izbrali kulise iz tega albuma, nato pa so jih v gledališki delavnici za posamezno predstavo priredili ali pa celo predelali (preslikali, jim spremenili obliko). ${ }^{12}$

Po kritikah sodeč so bile pri prvi uprizoritvi Kralja na Betajnovi sporne predvsem spremembe luči ${ }^{13}$, sicer pa je bila predstava za "povojne razmere dovolj dobro pripravljena« (Debevec, 1967, 12).

Naslednja uprizoritev Kralja na Betajnovi je bila že leta 1922, in sicer v režiji Milana Skrbinška (11. 12. 1922, režija: Milan Skrbinšek, SNG Drama Ljubljana). Z njo je ljubljanska Drama praznovala obletnico Cankarjeve smrti. Skrbinšek je bil tedaj znan kot oboževalec Cankarja in mojstrski interpret njegovih likov. V igri je šel od romantičnega zanosa k psihološkemu

11 Šele 30. 6. 1919 je namreč gledališki konzorcij na seji angažiral Vaclava Skrušnyja za šefa gledaliških slikarskih delavnic. Kot scenograf mu je leta 1920 pomagal tudi slikar in lutkar Milan Klemenčič.

12 Zaradi večnega pomanjkanja finančnih sredstev v ljubljanskem gledališču je stari »fundus" ostal v rabi vse do druge svetovne vojne, vsaj pri manj pomembnih predstavah.

13 Lipah, F., »Kralj na Betajnovi« v Narodnem gledališču, Ljubljanski Zvon, 1919, str. 60: »Izpremembe luči so bile gorostasne..." 
realizmu. Pri režiji pa se je poglobil v pomen in simboličnost besedila. V prvi povojni sezoni je, kot sem že omenila, kot ravnatelj in režiser tržaškega gledališča na njegovem odru prirejal večere Cankarjevih del. In čeprav je bil znan kot "razgledan in razmišljajoč ustvarjalec" ter "režiser poglobljenih dramskih besedil« (Moravec, 1980, 120-121), je kritika njegovega Kralja na Betajnovi v ljubljanski Drami označila kot slabo uprizoritev (Koblar, 1964, 118).

Sledil je kar dolg premor in naslednjič so to delo na odru ljubljanske Drame uprizorili v režiji Cirila Debevca (26. 9. 1931, režija: C. Debevec, SNG Drama Ljubljana). Tudi Debevec je bil znan kot ljubitelj Cankarjevih del. Pri njihovih uprizoritvah se je še bolj kot Skrbinšek posvečal notranji režiji. Tako je Vodnik opazil, da je pri režiji Kralja na Betajnovi predvsem iskal "skladnost med gledališčem in pesnikom" (Vodnik, 1968, 21), v katerem je Koblar videl »korak naprej« (Koblar, 1965, 63). Ohranili sta se tudi fotografiji predstave. Iz njiju lahko razberemo, da je sicer šlo za dve različni prizorišči (obe prizorišči sta bili notranjščini krčme), ki pa sta bili postavljeni s kulisnimi stenami. Delo je bilo spet postavljeno s »plahutajočo sceno« v prostor »italijanske škatle«.

Zadnja uprizoritev Kralja na Betajnovi v ljubljanskem gledališču je bila hkrati tudi zadnje uprizorjeno Cankarjevo delo pred začetkom druge svetovne vojne. Delo je režiral mariborski režiser Jožko Kovič (20. 6. 1942, režija: J. Kovič, SNG Drama Ljubljana). ${ }^{14}$ Pri scenografiji mu je pomagal inž. arh. Ernest Franz. Kljub temu da so se v tistem času slovenski scenografi že spogledovali s funkcionalističnim snovanjem odrskega prostora, pa sta režiser in scenograf, sodeč po ohranjeni fotografiji, uporabila kulise, $s$ katerimi sta obdala prostor krčme. Uprizoritev je France Vodnik ocenil kot »dosledno realistično podajanje«(Vodnik, 1968, 130), sicer pa je predstava doživela velik uspeh.

V ljubljanski Drami so si bile torej vse štiri postavitve Kralja na Betajnovi scensko podobne in zaradi tipične kulisne postavitve tudi scensko manj za-

14 Zaradi nemške zasedbe Maribora je večina mariborskega ansambla pobegnila v Ljubljano. Mariborski ansambel je v Ljubljani v 24. gledališki sezoni (1941-1942) uprizoril zadnji dve predstavi. Poleg Cankarjevega dela je Kovič režiral še Niccodemijevo »Učiteljico" (18. 7. 1942). 
nimive. Režiserji so se pri njihovih upodobitvah bolj kot na zunanjo režijo osredotočili na notranjo, se pravi na poglobljeno seciranje besedila in uprizoritev avtorjevih misli. Prav tako so to Cankarjevo delo v »plahutajoči sceni« postavljali tudi mariborski režiserji, na primer Jožko Kovič leta 1938.

Popoln odmik od scenskega dogajanja na poklicnih odrih pa je pri uprizarjanju Kralja na Betajnovi storilo gledališče sv. Jakoba v Trstu. Tu je okrog leta 1926 kot scenograf deloval Avgust Černigoj. Njegov scenski osnutek za Kralja na Betajnovi je nastal leta 1926. Kljub temu da je v drugih Černigojevih scenskih osnutkih za Šentjakobski oder, ki so nastali okrog 1926, čutiti močne vplive avantgardnih gledaliških gibanj, tako gledališke delavnice $\mathrm{v}$ Bauhausu kot tudi ruskega konstruktivizma, nas tu Černigoj preseneti, saj gre za preprosto ekspresionistično obarvano scensko upodobitev. Lahko bi celo dejali, da je to njegovo najbolj klasično scensko delo, pri katerem ne moremo govoriti niti o vplivih gledališke delavnice na Bauhausu niti o vplivih ruskega konstruktivizma. V scenskem osnutku za Kralja na Betajnovi lahko vidimo predvsem vplive drugih uprizoritev Cankarjevih besedil. Oder sv. Jakoba, za katerega je osnutek verjetno nastal, je bil namreč naslednik pogorelega tržaškega gledališča, kjer je postavil režijske in scenske norme za uprizoritve Cankarjevih del Milan Skrbinšek. Zato je Černigoj verjetno moral ljudem prikazati Cankarja takega, kot so ga bili vajeni. Vendar je bila, gledano $s$ tega stališča, Černigojeva zamisel vseeno moderna. Bolj ali manj je bila namreč ekspresionistična. Najbolj so morda izstopale le stopnice na desni strani, ki so spominjale na avantgardne poskuse bauhausovskega scenografa Oskarja Schlemmerja (na primer »Grosse scene«), čeprav je bolj verjetno, da se je tu Černigoj naslonil na Appiajeve scenografije. Drugače pa je scenska postavitev v celoti spominjala na scenografijo, ki jo je dve leti pozneje, leta 1928, na odru ljubljanske Drame za uprizoritev Cankarjevega Pohujšanja $v$ dolini šentflorjanski ustvaril scenograf Vaclav Skrušny (26. 9. 1928, režija: M. Skrbinšek, scenografija: V. Skrušny ml., SNG Drama Ljubljana). Skrušny si je namreč zamislil ekspresionistično sceno, ki je močno spominjala na dela sočasnih slovenskih ekspresionističnih slikarjev, predvsem na dela mariborskega slikarja Franja Stiplovška in njegovo tesnobno upodobitev ambienta v ciklu Stari Maribor iz leta 1924. Je šlo torej pri Černigojevi sceni za duha časa, vpliv sodobnega slovenskega slikarstva ali za nepisano pravilo, kako upodobiti Cankarja? 
Kmalu po Kralju na Betajnovi so v prvi sezoni v Ljubljanski Drami uprizorili Jakoba Rudo (29. 1. 1919, režija: A. Cerar - Danilo, SNG Drama Ljubljana). Režiser predstave je bil spet Anton Cerar - Danilo. Ker se slikovno gradivo predstave ni ohranilo, lahko domnevamo, da je režiser tako kot že pri Kralju na Betajnovi tudi tu uporabil enotno prizorišče in kulisno sceno. Enotno prizorišče je določil kar Cankar sam, in sicer naj bi predstavljalo sobo "z glavnim vhodom na desni« (Cankar, 1900, 11). Kritiki pa očitno nad postavitvijo niso bili navdušeni, saj lahko beremo, da je bila to »neverjetno zanikrna uprizoritev dramatično šibkega Jakoba Rude» (Debevec, 1967, 13).

Do začetka druge svetovne vojne je ta Cankarjeva drama le še enkrat prišla na ljubljanski oder, in sicer jo je ob petdesetletnici Cankarjevega rojstva leta 1926 režiral Milan Skrbinšek. Na žalost se fotografsko gradivo ni ohranilo. Predstava pa, sodeč po kritikah, ni zadovoljila občinstva (Koblar, 1964, 187).

Za Jakobom Rudo so na repertoar ljubljanske Drame prišli Hlapci. Delo, ki je bilo krstno uprizorjeno na odru Slovenskega gledališča v Trstu v režiji Milana Skrbinška (1918-1919), je bilo med obema vojnama kar štirikrat uprizorjeno na odru ljubljanske Drame. Prav tolikokrat pa tudi na odru mariborskega gledališča. Med svoje predstave na Delavskem odru je Hlapce uvrstil tudi Ferdo Delak.

S premiero Cankarjevih Hlapcev (11. 12. 1919, režija: O. Šest, SNG Drama Ljubljana) je režiser Osip Šest odprl drugo gledališko sezono v ljubljanski Drami. Pozneje se je Šest rad spominjal njene uprizoritve: »Visoke stopnice. Ob straneh in zadaj zavese. Spredaj siv portal s transparentnim trikotom preko vse odprtine odra in ta kaže sceno. Najprej: oddaljeni griči, cerkvica, gostilna. Potem: konferenčna soba: na obeh straneh na stopnicah visoke omare. V trikotu spredaj knjige, šola, zvonec ... Jermanova soba, zastor $v$ ospredju ... zgoraj pokrajina prvega dejanja na jesen ... če služi ilustraciji. Hlapci rastejo, padajo ... gredo navzdol ... Le Jerman, Lojzka in župnik ostanejo ... konec je vizionaren ... hoče luči in zvoka ... Morda nekoč, o priliki, ko nastane potreba ..." (Šest, 1924, 80).

Ohranila se nam je fotografija predstave, ki prikazuje 4. dejanje. Z nje lahko razberemo, da je šlo še vedno za kulisno scensko postavitev. Prostor odra, »italijansko škatlo«, je Šest prvič pri nas poglobil, in sicer z novo sobo 
v ozadju. To je opazila tudi kritika: »Kar je dala očesu v IV. dejanju poglobitev $v$ prostor $z$ novo posebno sobo, je razdrla slaba gostilniška množica. Cankarja še čakamo (Koblar, 1964, 119). O preostali inscenaciji predstave pa piše Mirko Mahnič, ko navaja zapisnik 26. seje uprave Narodnega gledališča, v katerem se je o predstavi ohranilo slednje: "... Cankarjevi Hlapci: otvoritvena predstava, eno sobo preslikati $v$ tipično kranjsko izbo, en prospekt s Šmarno goro ..." (Mahnič, 1971, 52).

Prav tako so s Hlapci v ljubljanski Drami odprli deveto gledališko sezono. Tokrat je delo režiral Milan Skrbinšek (4. 10. 1926, režija: M. Skrbinšek, SNG Drama Ljubljana). Od predstave so se ohranile le kritike, ki so govorile o tem, da je Milan Skrbinšek »igro zaokrožil z izrednim umevanjem in tenkim čutom « (Koblar, 1964, 200), vendar pa »središče drame ni bilo povsem močno in jasno« (Koblar, 1964, 232).

Leta 1934 pa je Hlapce režiral Ciril Debevec (9. 10. 1934, režija: C. Debevec, scenografija: E. Franz, SNG Drama Ljubljana), ki je o svoji zamisli zapisal: "Kadar kaj režiram, imam vedno samo en poseben namen, in sicer vedno isti namen: postaviti delo na oder $v$ čim boljši in jasnejši obliki, to se pravi čim bolj podobno tisti sliki, ki jo nosim o delu $v$ svojih mislih in svojih čustvih. Drugih namenov nimam« (Debevec, 1934/1935, 29).

Tudi Debevec se je torej bolj kot z zunanjo režijo pri uprizoritvi ukvarjal $z$ duhovno realistično podobo Cankarjevega dela. In prav nič ni pomagalo, da je $\mathrm{z}$ režiserjem sodeloval znameniti scenograf Ernest Franz. Koblar je v inscenaciji videl nekoliko preveč poudarjeno simetrijo in predlagal boljšo rešitev, da bi prostor obrnili za 45 stopinj (Koblar, 1965, 207). Motilo ga je tudi to, da je koncentracija vsebine preveč poudarila koncentracijo prostora, pri tem pa zanemarja gledalčev občutek o življenju in svetu za odrom. Pohvalil pa je scensko iluzijo v III. in IV. dejanju (Koblar, 1965, 207).

Zadnja uprizoritev Cankarjevih Hlapcev v ljubljanski Drami pred drugo vojno je bila podobna prejšnji iz leta 1934. Ponovno sta jo namreč na oder postavila režiser Ciril Debevec in scenograf Ernest Franz, in sicer 2. februarja 1939, na dan, ko je Drama praznovala dvajsetletnico svoje samostojnosti. Tokrat je bilo besedilo močno cenzurirano, kajti ravno tedaj se je spet zaostrila cenzura. Imenovan je bil celo cenzurni svet, ki je črtal vse, kar je bilo politično spornega. Tako so tudi Hlapci (2. 2. 1939, režija: C. Debevec, 
scenografija: E. Franz, SNG Drama Ljubljana) doživeli okrnitev besedila, kar je "zbudilo mnogo ogorčenja» (Vodnik, 1968, 91). Drugače pa je Debevčeva režija »ob skromnih vnanjih sredstvih - inscenacijo je ubrano oskrbel inž. arh. Franz - živo ponazarjala notranjo podobo drame" (Mrzel, 1998, 147). Drama je bila tokrat namenjena tudi za gostovanje v Mariboru.

Tudi na mariborskem odru so Hlapce uprizorili kar štirikrat. V sezoni 1934/1935 jih je na primer uprizoril Jože Kovič (4. 10. 1934, režija: J. Kovič, SNG Drama Maribor). Odrska tla je s stopnicami in praktikabli dvignil ter razdelil na tri $\mathrm{v}$ različne višine postavljene igralne ploskve. $\mathrm{V}$ ozadje pa obesil velik bel prospekt $\mathrm{z}$ drevesom na levi strani.

Najbolj izvirna scenska upodobitev Cankarjevih Hlapcev med obema vojnama pa je bila gotovo stvaritev režiserja Ferda Delaka (15. 10. 1933, režija: F. Delak, Delavski oder, Ljubljana). To je bila hkrati tudi zadnja predstava, ki jo je naredil za Delavski oder v Ljubljani. Režijsko si je predstavo zamislil kot provokativno ter iz Cankarjevega besedila izpustil vse, kar ni bilo satirično ali družbeno kritično. Tako je v celoti izpustil peto dejanje. Se pravi, da je v predstavi prikazal vse tiste prizore, ki jih je v ljubljanski Drami leta 1939 skušal prepovedati cenzurni svet. Zmanjšal je tudi število oseb na odru. Tako je predstava gledalcem, ki besedila niso poznali, kazala zgrešeno podobo o delu. Scensko pa je bila povsem moderna. Scena je namreč kazala močne vplive tujih avantgardnih gledališč. Pri njej so uporabljali tako »vzvišek « kot tudi pogrezalo. Prizore pa je Delak med seboj povezal s projekcijami. Z reflektorji, s katerimi je krožil od osebe do osebe, je še stopnjeval satiro. Iz odrskega ozadja se je slišal odmev nevidnega zbora, ki je ponavljal najbolj značilne besede izgovorjene na odru. Simbolično je Delak uporabil tudi dva zastora: belega in črnega. Sam je o predstavi zapisal: „Zlasti s Hlapci sem izvedel poskus. Iztrgal sem iz vsega dejanja le moment hlapčevstva in le to podaril ljudem« (Moravec, 1971, 84).

Mnogo bolj kakor pri prejšnjih uprizoritvah Cankarjevih dramskih del so se režiserji pa tudi scenografi ukvarjali s scenskimi postavitvami Pohujšanja $v$ dolini šentflorjanski. Prvo uprizoritev tega dela na odru ljubljanske Drame je režiral Osip Šest (20. 5. 1920, režija: O. Šest, SNG Drama Ljubljana). Po ohranjeni fotografiji sodeč, je Šest očitno skušal delo scensko upodobiti popolnoma po Cankarjevih navodilih. Kot je opazil tudi France Koblar, se je naslonil celo na Cankarjev opis scene v tretjem dejanju (Ko- 
blar, 1964, 53). V njem se je namreč pisatelj ponorčeval iz odrske opreme ljubljanskega gledališča pred prvo svetovno vojno. ${ }^{15}$ Ohranjena fotografija prikazuje prav tretje dejanje. Baročno in rokokojsko oblikovane kulise se seveda niso ujemale z dogajanjem na odru, na katerem so, če povzamemo kritika, igralci igrali kot "marionete» (Koblar, 1964, 53). Koblar je predstavo povezal tudi s slovensko likovno umetnostjo, ko je zapisal: »V resnici se je zdelo, da so oživele Smrekarjeve karikature (Koblar, 1964, 43). Tokrat je med gledališkimi kritiki o sceni predstave pisal tudi Josip Vidmar. V reviji Kritika je zapisal: »Šest sam je na primer v prvem dejanju proti Cankarju odprl spalnici vrata, tako da se županja slači na odru, kar preostro in grdo efektno podčrtava Cankarjevo že dovolj neprikrito izraženo misel. V drugem dejanju je uvedel domislek z blazinami... Prav tako je tisto neumno odevanje sirote in kopičenje pohištva pred vrata« (Vidmar, 1925/26, 73).

Pri predstavi so se gledalci srečali celo s tako nemoralnim prizorom, kot je županja, ki se slači na odru. Hkrati pa je Šest že skušal predstave oblikovati s svetlobnimi efekti: »Svetlobni efekt iz zadnjega dejanja je pa ponovitev že stare Šestove bolezni; tu samo trga potek dogodkov, pove pa toliko kot nič" (Vidmar, 1925/26, 74).

Posebno zanimiva je bila scenografija Pohujšanja, ki jo je postavil V. Skrušny (26. 9. 1928, režija: M. Skrbinšek, scenografija: V. Skrušny, SNG Drama Ljubljana). Ohranjeni so trije njegovi scenski osnutki, ki popolnoma ekspresionistično označujejo odrski prostor. Tesnobno občutenje prostora, ki ga je dosegel z menjavo svetlobe in senc, poudarjenimi diagonalami in ostrimi koti, nas takoj spomni na dela slovenskih ekspresionističnih slikarjev. Tu mislim predvsem na dela mariborskega slikarja Franja Stiplovška in njegovo tesnobno upodobitev ambienta v ciklu Stari Maribor (1924). Vendar bi lahko pri tej scenografiji govorili tudi že o vplivu Černigojevega scenskega osnutka za Kralja na Betajnovi, nastalega okoli leta 1926. Popolnoma mogoče je namreč, da je vplival na mladega Skrušnyja, ki je bil izobražen slikarsko in scensko.

15 Cankar (Cankar, I., Pohujšanje v dolini šentflorjanski, Ljubljana 1993, str. 64.) je sceno tretjega dejanja v didaskalijah opisal takole: »Velika dvorana, tako bogato in gosposko opremljena, kakor zmore ljubljansko gledališče. Oprema je kričeča, naravnost groteskna, kakor na kup znešena iz vseh neverjetnih krajev in izb. Zadaj velika okna in steklena vrata na vrtno verando." 
S Skrušnyjevim scenskim osnutkom je naša scenografija spet doživela enega izmed svojih umetniških vrhov in nadaljevala tradicijo sodobno opremljenih predstav prejšnjih sezon (konstruktivistične scene Čapkovega R. U. R. (1922), ekspresionistično-novostvarnostne Langerjeve Periferije (1925) in ekspresionistično-nadrealistične postavitve Cerkvenikove Roke pravice (1928)).

Koblar je v kritiki o predstavi zapisal, da je bila uprizorjena $\mathrm{v}$ »novi, netradicionalni in celo protitradicionalni režiji Milana Skrbinška, ki je zame še danes najboljša uprizoritev Cankarjeve farse (Koblar, 1964, 314). Motilo ga je predvsem to, da so morali biti igralci preveč podrejeni sceni, tudi v tem, da so ves čas predstave prihajali na oder in odhajali $\mathrm{z}$ njega iz iste smeri. Poudaril pa je še, da bi bilo treba v tretjem dejanju več razkošja, pri čemer se je kritik zavedel, da je za to spet krivo pomanjkanje denarja (Koblar, 1964, 314). Če povzamemo po Moravcu, je bila predstava tudi za druge kritike "najzanimivejši produkt slovenske gledališke umetnosti po vojni sploh«(Moravec, 1996, 182).

Pohujšanje (17. 9. 1933, režija: O. Šest, scenografija: V. Uljaniščev, SNG Drama Ljubljana) je prišlo spet na spored ljubljanske Drame v sezoni 19331934 in je med predstavami te sezone scensko najbolj izstopalo. Ohranila sta se barvna scenska osnutka, ki kažeta prvi in tretji akt. Na prvem scenskem osnutku je Uljaniščev naslikal županovo krčmo. Odprl je eno izmed sten hiše (tisto na odrski rampi) tako, da je občinstvo lahko hkrati s fasado in leseno streho krčme gledalo tudi v njeno notranjost, v županovo krčmo in skrajno desno tudi v njegovo izbo. Drugi scenski osnutek pa je nastal za tretji akt Cankarjeve farse. V didaskalijah tega akta se je Cankar, kot rečeno, ponorčeval iz slabih tehničnih razmer našega odra. ${ }^{16}$ Vendar pa se tokrat scenograf ni naslonil na njegov predlog. Naredil je sicer veliko dvorano, ki pa ni bila okrašena, kot predlaga dramatik, bila je celo zanemarjena. S stropa so visele pajčevine, $v$ njenem desnem zgornjem kotu je velik črn pajek pletel mrežo. S sten se je luščil omet. Vhod v sobo, ki je bila nekdaj verjetno veličastna, pa je bil zgoraj zabit $\mathrm{z}$ lesenimi deskami. Tudi velikih oken in steklenih vrat na vrtno verando postavitev ni imela. Uljaniščev je namreč v odrskem ozadju za slavnostno mizo naredil le velikansko odprtino s pogle-

16 Glej op. 21. 
dom na vrt. Nad mizo pa je visela svetilka v obliki netopirja. Tako je dajala scena bolj kot tisto kričavo grotesknost, ki jo je v tekstu zahteval Cankar, srhljiv vtis.

O scenski postavitvi drugega dejanja, ki se dogaja v Petrovi kolibi, pa je v Gledališkem listu pisal režiser Šest. Najprej je Petrovo kolibo postavil v gozd, potem pa jo je na začetku dejanja obrnil z zadnjo steno proti občinstvu tako, da je pod oknom škilil zlodej in govoril del svojega monologa (Ost, 1933/34, 2). Kritikom je bila predstava scensko zanimiva. Vodnik je zapisal: »Tako je bila npr. posrečena njegova zamisel, da razširi prostor $v 2$. dejanju. Zato pa je bil tembolj neokusen prizor z županjo v kamri« (Vodnik, 1968, 59).

Zadnjič je to Cankarjevo delo prišlo na oder ljubljanske Drame tik pred začetkom druge svetovne vojne. Osip Šest se je pri uprizoritvi (23. 9. 1940, režija: O. Šest, scenografija: E. Franz, SNG Drama Ljubljana) naslonil na svoje prejšnje režije. Sceno mu je pomagal oblikovati Ernest Franz. Ohranile so se tudi fotografije predstave, ki pričajo, da je imelo vsako dejanje svojo scensko postavitev, natančno tako, kot je svetoval Cankar v didaskalijah. Pri prvih dveh dejanjih je scenograf popolnoma sledil avtorjevim zamislim. Tako je v prvem aktu postavil županovo krčmo, »ki je opremljena, kakor so opremljene gosposke krčme na deželi« (Cankar, 1993, 35). V drugem aktu pa Petrovo kolibo: "Izba je velika, ampak zelo nizka in strahovito razmetana; strop je lesen in začrnel; tla so prstena; $v$ kotu napol podrta peč; ob stenah vegaste klopi; na levi, tik pod pečjo, velika blazina na tleh. Ampak drugače je $v$ izbi vse polno in natlačeno bogatega pohištva, kakor da se je bil zvrnil vanjo tovoren voz; velik divan, mehki stoli, ogledala, preproge, pisane odeje, celo bleščeč lestenec - vse prevrnjeno in nakopičeno, tako da so duri na desni napol zastražene. Sredi ozadja je nizko okno" (Cankar, 1993, 50). Šele v tretjem dejanju, v katerem se je Cankar ponorčeval iz opreme ljubljanskega odra pred prvo svetovno vojno, si je scenograf dovolil malce svobode. Oder je razdelil na dva dela. Sprednji del je predstavljal "slavnostno veliko dvorano", ki je imela na stranskih stenah naslikane polkrožne loke, na stropni sofiti pa iluzionistično naslikan odpadajoč omet. Velik polkrožni lok, ki je poslikan spominjal na cerkveni slavolok, se pravi na mejnik, ki vodi iz cerkvene ladje v oltarni prostor, pa je tu ločeval dvorano od vrtne verande. Verando je scenograf postavil $v$ odrsko ozadje in jo s stopniščem mogočno dvignil nad 
prednji del odra, tako da so gledalci lahko natančno spremljali dogajanje tudi v odrskem ozadju. Problem postavitve dreves je rešil s poslikanimi in v drevesa spremenjenimi kulisami, s katerimi je obdal ozadje verande. Scena je bolj kot na slavnostno dvorano spominjala na vrata v pekel - razpadajočo arhitekturo. S tem je simbolno dopolnila Cankarjevo besedilo v tretjem dejanju, ko se na veliki svatbi pojavi konkordat, ki s šepanjem spominja na hudiča. Zlodejev govor v tretjem dejanju je režiser poudaril tako, da ga je postavil pred glavni zastor in ne le $\mathrm{v}$ odrsko ospredje.

Tako kot v Ljubljani so tudi na odru mariborske Drame v času med obema vojnama štirikrat uprizorili Pohujšanje. Od teh predstav sta bili scensko najbolj zanimivi dve, Bratinova in Kovičeva uprizoritev.

Valo Bratina je namreč pri scenski postavitvi Cankarjevega Pohujšanja $v$ dolini šentflorjanski (5. 10. 1924, režija in scenografija: V. Bratina, SNG Drama Maribor) pometel s staro scenografijo in odrsko opremo. Uporabil je zavese, velika okna in lampijone.

Kovičeva scena (2. 10. 1929, režija: J. Kovič, SNG Drama Maribor) pa je bila usmerjena v popoln ekspresionizem. Odrski okvir je bil narejen iz kulis nepravilnih oblik, ki so tridimenzionalno segale v odrski prostor. Na levi in desni strani so bile kulise poslikane s hribčki, na katerih so bile cerkvice. Na stropni sofiti je bilo naslikano nebo in karikirana božja podoba - pajek $\mathrm{Z}$ veliko glavo in šestimi nogami, ki vse vidi in bdi nad pohujšanjem. V zaključnem prizoru pa je na sredini odra stala nepravilno, v ostre kote obrezana kulisa, poslikana $\mathrm{z}$ lilijami, simbolom čistosti. $\mathrm{Z}$ obema stranskima kulisama in tisto $\mathrm{v}$ sredi, $\mathrm{z}$ lilijami, je nastal nekakšen karikiran portalni vhod, ki bi ga lahko razlagali tudi kot karikirana "porta coeli« gotskih cerkva - seveda v tem primeru vrata niso vodila v nebesa, temveč v pekel.

Cankarjevo delo Za narodov blagor je bilo na odru ljubljanske Drame $\mathrm{v}$ času med obema vojnama uprizorjeno trikrat. Prva predstava je bila leta 1920 in jo je režiral Osip Šest (16. 9. 1920, režija: O. Šest, SNG Drama Ljubljana). Druga uprizoritev je bila leta 1925, in sicer pod režijsko taktirko Milana Skrbinška (11. 11. 1925, režija: M. Skrbinšek, SNG Drama Ljubljana). Tretjo pa je režiral Bojan Stupica (24. 9. 1936, režija in scenografija: B. Stupica, SNG Drama Ljubljana). Od treh predstav je imela le zadnja tudi scenografa (Stupica sam). 
Prva, Šestova uprizoritev je bila označena kot »neskladnost brez pravega učinka« (Koblar, 1964, 57). Druga, Skrbinškova režija, pa je Stupici naložila težko nalogo, saj so jo tedanji sodobniki ocenili za "režijsko brez dvoma najboljšo uprizoritev Cankarja, kar smo jih kdaj imeli na ljubljanskem odru« (Debevec, 1967, 15). Skrbinšek je bil res mojster pri uprizarjanju Cankarja, hkrati pa je imel za seboj kar nekaj uprizoritev tega avtorja (tudi na odru pogorelega Slovenskega gledališča v Trstu). Stupica se je sicer bolj osredotočil na notranjo režijo (na oder je postavil žive, resnične osebe in situacije), vendar pa se je poglobil tudi v realistično oblikovanje odrskega prostora, kar je opazil tudi kritik: »Pri naši uprizoritvi se režiser in arhitekt med sabo že precej dopolnjujeta (Pavšič, 1973, 151). Klasično scensko postavitev notranjega prostora je moderniziral. Tudi tokrat, čeprav je šlo le za interier, prostora ni več slikal, ampak ga je gradil, in sicer s praktikabli, mostovži, stopnišči, ograjami, zalomljenimi, vdrtimi in izbočenimi stenami ter zavesami. Postavil je pravo arhitekturo z mostovžem in balkonom ter stopniščem. Tako je nastala tudi zadnja stena, ki je bila grajena v višino. $S$ stopniščem in mostovžem je namreč dobil tudi prvo nadstropje in s tem dodaten igralni prostor. Edino, kar je motilo, je bila prevelika razdalja med vrati nad stopniščem in sredino odra. Vplivala je namreč na nepremišljeno beganje velikega števila igralcev po odrskem prostoru in zmotila tempo prvega dejanja. Scena je kazala nekoliko stiliziran, preprost realizem. Šlo je za popolnoma novo realistično zgradbo prostora. To ni bil tisti realizem, ki smo ga bili vajeni iz predstav prvih povojnih let, s katerim so oder zaznamovali v naturalizem usmerjeni gledališčniki. Šlo je za novi odrski realizem, slog, ki je ustrezal novorealistični miselnosti v sočasni likovni umetnosti in literaturi. ${ }^{17}$

Poleg novega sloga je Stupica na oder ljubljanske Drame vpeljal še eno novost. V skladu z avantgardno miselnostjo je namreč skušal združiti prostor za gledalce $\mathrm{z}$ odrskim prostorom oziroma gledalce popolnoma vključiti v dogajanje na odru. Avantgardni umetniki (tudi Černigoj pri scenski postavitvi za Andrejevo Anfiso leta 1926 na goriškem odru) so si pri tem pomagali z dolgimi mostovži in platformami, ki so jih postavljali v parter med

17 Na primer v literaturi pri Edvardu Kocbeku, v likovni umetnosti pa v delih Vena Pilona in Franja Stiplovška. 
občinstvo, in potem na njih igrali. V nasprotju z njimi si Stupica tu ni pomagal s scenskimi pripomočki. Med oder in publiko je v vrsto postavil statiste, ki so med predstavo bučno demonstrirali. Upal je, da bo gledališko občinstvo $s$ tem spodbudil k demonstracijam. Vendar se je uštel. Kot piše Pavšič, med publiko ni bilo nikakršnega odziva. ${ }^{18}$ Uspešna Stupičeva postavitev pa je požela pohvalo kritike: "Za narodov blagor sodi po svoji kvaliteti med zelo dodelane, najpreciznejše Stupičeve uprizoritve (Pavšič, 1973, 150).

O scenski postavitvi Romantičnih duš (6. 10. 1922, režija: M. Skrbinšek, SNG Drama Ljubljana), ki jih je na odru ljubljanske Drame uprizoril Milan Skrbinšek, se ni ohranilo nobeno pričevanje. O uprizoritvi dramatizacije Cankarjevega Hlapca Jerneja in njegove pravice (15. 10. 1927, režija: M. Skrbinšek, SNG Drama Ljubljana) na ljubljanskem odru pa so kritiki zapisali, da je režiser mešal simbolizem $\mathrm{z}$ realistično igro na pretežno kubistično-futuristični sceni (Koblar, 1964, 271). Žal slikovno gradivo predstave ni ohranjeno. Ferdo Delak je predstavo ocenil takole: »Skrbinškov Hlapec Jernej je izgubil vso učinkovitost in ni bil režijsko ne realističen ne stiliziran ..." (Moravec, 1971, 44).

Na mariborskem odru je uprizoril Hlapca Jerneja (7. 2 .1926, režija in scenografija: V. Bratina, SNG Drama Maribor) Valo Bratina. Pri scenski postavitvi je poleg zaves in velikih oken uporabil še "vbočen horizont«, kar je bila za mariborski oder glavna novost. Inscenacija je vsebovala tako ekspresionistične kot tudi konstruktivistične elemente. Kritik Božidar Borko pa je o njej zapisal: "Oder je urejen horizontalno in obdan z gubastimi zavesami. Izprememba mesta se označuje le z neznatnimi konturami dekorja, okvir pa ostane enak skozi vso igro. Taka inscenacija ima to prednost, da ne razblinja gledalčeve pozornosti na interier sob ali na pokrajino, marveč ga sili, da se osredotoči na osebe in dejanje; nekam mistična scena pa še podžge domišljijo in dvigne iluzionarnost« (Borko, 1926).

Bolj znana in scensko zanimiva pa je bila vsekakor Delakova uprizoritev tega Cankarjevega dela (23. 5. 1932). Delak je odlomek Oče naš iz tega dela bral že na večeru v Gorici, ki sta ga pripravila skupaj z Avgustom Černigojem pod okriljem društva Adria. Zdaj pa se je odločil za celovečerno pred-

18 Pavšič, V., Ivan Cankar: »Za narodov blagor«. Zapiski ob premierah, in: V. Pavšič - M. Bor, Izbrana dela I, Ljubljana 1973, str. 148. 
stavo. Uprizorjena je bila na odru ljubljanske Opere, šlo pa je za delavsko predstavo. Pri njeni scenografiji je Delak uporabljal diapozitive, praktikable $\mathrm{v}$ vseh mogočih nivojih, izbrane svetlobne efekte in glasbo. Igralci so bili oblečeni v delavske obleke. Kipar Nikolaj Pirnat je v Jutru zapisal: »Včerajšnja prireditev Delavskega odra Svobode v opernem gledališču je bila dogodek, kakršnega $v$ tem hramu normalnih predstav in gostovanj vsake sorte že dolgo ni bilo" (Moravec, 1971, 74). S predstavo je Delak uspešno gostoval po Sloveniji in bil z njo tudi v Zagrebu.

Kot zadnje Cankarjevo delo je po prvi svetovni vojni prišla na spored Lepa Vida (11. 12. 1928, režija: C. Debevec, SNG Drama Ljubljana). Popolnoma realistično uprizorjeno Cankarjevo dramo je Debevec postavil med razpadajoče zidove znamenite Cukrarne. Čeprav je bil režiser ves čas svojega odrskega snovanja pravi pristaš ekspresionizma, ${ }^{19}$ pa je pri postavitvi scene tokrat sledil besedilu. Zato Cukrarna in zato čisti realizem. Predstavnik mlajše generacije Bratko Kreft je v kritiki o predstavi Lepe Vide zapisal: »Nežni simbolizem Lepe Vide (se) ni mogel najti v naturalistični sceneriji $($ Kreft, 1965, 46). Koblar pa je imel popolnoma drugo mnenje. Pisal je o "preprosti odrski mehaniki in realistični neokretnosti scenerije" (Koblar, 1964, 315).

Bolj sodobno scenografijo je imela uprizoritev Lepe Vide (22. 12. 1938, režija: F. Žižek, Okrajno gledališče Ptuj), ki jo je ob dvajseti obletnici Cankarjeve smrti v Okrajnem gledališču na Ptuju uprizoril Fran Žižek. Žižek je bil prepričan, da Lepa Vida doslej na odru ni uspela, ker so jo uprizarjali na »konvencionalno-realističen način " (Žižek, 2000, 203). Zato mu je pomenila velik izziv. Predstave se je lotil tako, da se je naslonil na Cankarjev simbolizem. Na odru je skušal prikazati hrepenenje, sanje in misli dramskih oseb. Pri scenski postavitvi si je pomagal z znanjem, ki ga je v Pragi dobil od znamenitega režiserja Buriana in njegovih postavitev v gledališču D36. Tako je najprej poenotil prizorišče in na njem uprizoril dve različni sferi, realno (predstavljala je študentsko podstrešno sobico) in irealno (ki je predstavljala svet hrepenenja in prividov). Namesto sten sobice je postavil

19 Že kot študent je na primer v pismu iz Prage zapisal, da so prebivalci Prage mnogo bolj zadovoljni z ekspresionizmom kot tisti v Ljubljani, vzrok pa naj bi bil, da »tukajšnji ekspresionisti niso Kogoji, Podbevški, Jakci idr. ampak Hasencleverji, Kaiserji ..." (Moravec, 1996, 74). 
prosojno tilasto tkanino, skozi katero so lahko gledalci gledali dogajanje za steno. Svet hrepenenja in vročičnih fantazij je še okrepil s senčnimi igrami in s filmskimi projekcijami. Na veliko filmsko platno v ozadju je projiciral iz odrskega ozadja proti publiki. S kinooperaterjem sta šla celo tako daleč, da sta iz številnih filmov sestavila skupaj nov film, ki je ilustriral vizije posameznih vlog.

O scenskih postavitvah Cankarjevih dram na slovenskih odrih lahko torej povemo, da so znotraj preostalega razvoja slovenskega scenskega oblikovanja doživljale svoj razvoj. Na razvoj slovenske scenografije so vplivali tudi sodobni slovenski likovni umetniki in literati. Med slikarji, scenografi, režiserji in literati so se stkala tesna prijateljstva (npr. mladostno prijateljstvo med Hinkom Smrekarjem in Hinkom Nučičem, ${ }^{20}$ pa prijateljstvo Avgusta Černigoja, Srečka Kosovela in Ferda Delaka, Cirila Debevca in Srečka Kosovela, Vala Bratine in Alojzija Remca, Stanka Majcna in Hinka Nučiča ...). Režiser Ciril Debevec je bil po materini strani celo sorodnik Riharda Jakopiča. ${ }^{21}$ Pomembno je bilo sodelovanje s slikarjem Ivanom Vavpotičem, ki je bil v letih 1926-1930 tudi glavni scenograf ljubljanskega Narodnega gledališča, in z drugimi slikarji, ki so vsaj enkrat sodelovali pri oblikovanju odra. To so bili: Matej Sternen, Milan Klemenčič, Maksim Gaspari, Božidar Jakac (v Operi), Saša Šantel (v Marionetnem gledališču, ilustriral je tudi platnice za prvo gledališko revijo Maska), Ivan Čargo, Avgust Černigoj in Nikolaj Pirnat - slikal je karikature igralcev in pomagal pri scenografiji za Haškovega Švejka (1928) v mariborski Drami. Likovni umetniki so bili tudi pogosti obiskovalci predstav. Hodili so predvsem v Klemenčičevo Marionetno gledališče, ${ }^{22}$ kamor jih je pogosto vabil sam ravnatelj. Nekaj jih

20 Oče Hinka Nučiča je bil birmanski boter Hinka Smrekarja. Glej Nučič, H., Igralčeva kronika I, Ljubljana 1960, str. 41.

21 Debevca je zanimalo tudi slikarstvo. V Pragi se je vpisal na "Deutsche Akademie für Musik und darstellende Kunst«. Moravec, D., Slovenski režiserski kvartet (z gostom), Ljubljana 1996, str. 73.

22 V literaturi so našteti: Maksim Gaspari, Rihard Jakopič, Veno Pilon, Saša Šantel in Ivan Vavpotič. Glej Kreft, M., Lutkar Milan Klemenčič in Gašperček, Dokumenti SGM, 27-28, 1973, str. 104. Veno Pilon je v mladosti pomagal pri marionetnih predstavah Milanu Klemenčiču v Šturjah pri Ajdovščini. Risal je osnutke za gledališka vabila (ohranjenih je pet) in scenske osnutke za likovne prizore (ohranjena sta dva). O tem Vuk, M., Doprinos k osvetlitvi pionirskega obdobja modernega slikarstva na Primorskem, Goriški letnik 3, 6, 1976, str. 199-203. 
je celo sodelovalo pri opremljanju marionetnega odra (Saša Šantel, ${ }^{23}$ Ivan Vavpotič $\left.{ }^{24}\right)$.

Sodelovanje gledaliških ustvarjalcev, likovnih umetnikov in literatov je vplivalo tudi na povezanost scenografije s sočasno literaturo in likovno umetnostjo in prispevalo k njenem likovnem razvoju. Slovenska scenografija je bila sprva oblikovana $\mathrm{v}$ okvirih realizma in naturalizma 19. stoletja. Že v dvajsetih letih 20. stoletja je začela slediti smernicam slovenskih ekspresionistov (vplivala sta predvsem brata Kralja in Veno Pilon) in prvih poskusov nove stvarnosti (kjer so vplivala dela slikarjev Franja Stiplovška in Vena Pilona). Z elementi nadrealizma, funkcionalizma in avantgardnega konstruktivizma pa je scenografija celo prehitela razvoj slovenske likovne umetnosti. Slovensko likovno umetnost so $\mathrm{z}$ avantgardnimi tokovi zaznamovala šele dela slikarja in scenografa Avgusta Černigoja po letu 1926.

Cankar je bil kot največji slovenski dramatik vedno deležen največje pozornosti gledaliških ustvarjalcev. Njegova dela so večinoma prišla na oder ob praznovanju obletnic (njegove smrti ali pa obletnic gledališč) in pa tudi, kadar je gledališče nameravalo gostovati po drugih gledališčih.

Večinoma so se režiserji pri uprizoritvah Cankarjevih del bolj kot v problematiko scenskih postavitev poglabljali v pomen in simboliko njegove pripovedi. Zato je razumljivo, da je imelo le redko katero njegovo delo (od številnih uprizoritev) tudi scenografa. Na ljubljanskem odru je tako scenografa imelo le pet uprizoritev. To so bile: Pohujšanje v dolini šentflorjanski - 1928 (Vaclav Skrušny mlajši); 1933 (Vasilij Uljaniščev); 1940 (Ernest Franz); Hlapci - 1934 (Ernest Franz) in Za narodov blagor - 1936 (Bojan Stupica).

Na splošno lahko rečemo, da je bilo oblikovanje scene pri Cankarjevih delih odvisno tudi od besedila. Tako so na primer Kralja na Betajnovi zaradi predpisane enotnosti dogajanja $v$ interieru ves čas postavljali med kulise, vizualno bolj barvite scenografije pa je dobilo Pohujšanje. Avantgardno na-

23 Naslikal je gozdno sceno za Berndorfovo orientalsko bajko "Zakleti kalif« (13. 12. 1921) in prospekt z Mestnim trgom v Ljubljani za Lahovo enodejanko »Čarobni dežnik«, ki je bila uprizorjena istega dne.

24 Naslikal je tudi zastorček Slovenskega marionetnega gledališča. 
strojenima Delaku in Žižku so ustrezali bolj Hlapci, dramatizacija Hlapca Jerneja in simbolistična Lepa Vida.

Likovno so najbolj izstopale Delakove in Žižkove scenske postavitve. Oba sta pod vplivom avantgardnih gledališč Cankarjeva besedila dopolnjevala s projekcijami diapozitivov ali pa filmov, s postavljanjem praktikablov $\mathrm{v}$ vseh mogočih višinskih nivojih, s posnetimi govori besedila, ki se ga je slišalo iz odrskega ozadja, ter s svetlobnimi efekti. Njune nove odrske stvaritve so občudovali tudi likovni umetniki. Tako je na primer o Delakovi uprizoritvi Hlapca Jerneja in njegove pravice na Delavskem odru (1932) v kritiki navdušeno pisal kipar Nikolaj Pirnat.

Zanimivo je, da je sicer scensko avantgardno usmerjeni Avgust Černigoj pri osnutku za Cankarjevo delo popustil tradiciji in postavil ekspresionistično sceno (Kralj na Betajnovi, 1926), ki je pozneje verjetno vplivala na Skrušnyjevo postavitev Pohujšanja (1928) v ljubljanski Drami. Avantgardne elemente pa je v sceno Za narodov blagor (1936) vključil Stupica. Interier je sicer deloval realistično - novostvarnostno (prostor enonadstropne stavbe v ozadju je bil zgrajen), vendar je vanj vpeljal temeljno avantgardno značilnost. S tem ko je postavil statiste, ki so demonstrirali, med oder in občinstvo, je namreč podrl četrto steno odra in s tem povezal publiko $\mathrm{z}$ dogajanjem na odru.

Druge scenske postavitve so bolj ali manj temeljile na ekspresionističnih elementih. Edina izjema je bila, sodeč po kritikah, kubistično-futuristična postavitev Cankarjevega Hlapca Jerneja (1922) v režiji Milana Skrbinška.

Tako lahko povzamemo, da so bile scenske postavitve Cankarjevih del v obeh Narodnih gledališčih (ljubljanskem in mariborskem) postavljene večinoma s kulisami. Vendar so bile tudi med njimi predstave, kot na primer Šestovo Pohujšanje v dolini šentflorjanski (1920), ki so jih kritiki primerjali s sodobno likovno umetnostjo. Pri Pohujšanju so omenjali predvsem karikature slikarja Hinka Smrekarja. Redke izjeme so imele ekspresionistično scenografijo. Tako je na primer Skrušnyjeva scenografija za Cankarjevo Pohujšanje $v$ dolini šentflorjanski (1928) kazala vplive ekspresionističnih motivov mariborskega mestnega slikarja Franja Stiplovška. Od vseh teh pa je odstopala Stupičeva realistično-avantgardna postavitev Za narodov blagor, v kateri je režiser s stavkajočimi statisti v parterju porušil nevidno mejo med igralci in občinstvom in jih povezal v celoto odrske uprizoritve. 
Gledalci so bili prvič pri nas postavljeni v središče odrskega dogajanja. Bolj zanimive in drzne scenske postavitve Cankarjevih del pa so se selile na Delavski oder in oder Okrajnega gledališča na Ptuju, kjer so z uporabo filmske umetnosti in diapozitivi celo presegli sočasno novostvarnostno oblikovanje v likovni umetnosti.

\section{LITERATURA}

B. B. (Borko, B.), Hlapec Jernej in njegova pravica, Tabor, 16. 2. 1926.

B.G. (Gavella, B.), O režiji Shakespear-ove komedije Kar hočete, Gledališki list ljubljanske Drame (GLLjD) 1931-1932, 15, str. 1-2.

C.D. (Debevec, C.), Razgovor o »Hlapcih «, Gledališki list ljubljanske Drame (GLLjD) 1934/1935, 4, str. 26-29.

Cankar, I., Jakob Ruda, Ljubljana, 1900.

Cankar, I., Pohujšanje v dolini šentflorjanski, Ljubljana, 1993.

Debevec, C., Izbrani gledališki članki, Knjižnica Mestnega gledališča ljubljanskega, Ljubljana, 1967.

Gavella, B., Igralec in gledališče, Knjižnica Mestnega gledališča Ljubljanskega, Ljubljana, 1968.

Jerman, I., Pričevanja o Ernestu Franzu, Dokumenti Slovenskega gledališkega muzeja 38-39 (1982), str. 117-118.

Koblar, F., Dvajset let slovenske Drame I (1919-1930), Ljubljana, 1964.

Koblar, F., Dvajset let slovenske Drame II (1930-1939), Ljubljana, 1965.

Kocjančič, A., Scenografija v slovenskih dramskih gledališčih med obema vojnama (1918-1941), Ljubljana 2005 (magistrsko delo, Oddelek za umetnostno zgodovino, Filozofska fakulteta, Univerza v Ljubljani, tipkopis).

Kozak, J., Gavellov Shakespeare, Jutro, 31. 3. 1932.

Kreft, B., Dramaturški fragmenti, Knjižnica Mestnega gledališča ljubljanskega, Ljubljana, 1965. 
Kreft, M., Lutkar Milan Klemenčič in Gašperček, Dokumenti Slovenskega gledališkega muzeja 27-28 (1976), str. 95-111.

Lipah, F., »Kralj na Betajnovi« v Narodnem gledališču, Ljubljanski Zvon, Ljubljana, 1919, str. 60.

Mahnič, M., Iz arhiva. Zgodovina gledališke cenzure na Slovenskem, Gledališki list ljubljanske Drame (GLLjD) 1949-1950, 10, str. 204-211.

Mahnič, M., Prispevek k podobi Narodnega gledališča v Ljubljani od 1920 do 1924, Dokumenti Slovenskega gledališkega muzeja 17 (1971), str. 40 57.

Moravec, D., Iskanje in delo Ferda Delaka, Knjižnica Mestnega gledališča ljubljanskega, Ljubljana, 1971.

Moravec, D., Slovenski režiserski kvartet (z gostom), Ljubljana, 1996.

Moravec, D., Slovensko gledališče od vojne do vojne (1918-1941), Ljubljana, 1980.

Moravec, D., Sprehod po razstavi, Dokumenti Slovenskega gledališkega muzeja 2 (1964), str. 42-80.

Mrzel, L., Gledališke kritike (1933-1939), Ljubljana, 1998.

Nučič, H., Igralčeva kronika I, Knjižnica Mestnega gledališča ljubljanskega, Ljubljana, 1960.

Ost. (Šest, O.), Cankar: Pohujšanje v dolini šentflorjanski, Gledališki list ljubljanske Drame (GLLjD) 1933-1934, 3, str. 1-2.

Pavšič V. - M. Bor, Izbrana dela I, Ljubljana, 1973.

Šest, O., O sceničnem ozračju, Dom in svet, Ljubljana, 1924, str. 80.

Vidmar, J., O Cankarjevem »Pohujšanju«, Kritika 1925-26, I/5, str. 73.

Vodnik, F., Kritična dramaturgija, Ljubljana, 1968.

Vuk, M., Doprinos k osvetlitvi pionirskega obdobja modernega slikarstva na Primorskem, Goriški letnik 3, 6, 1976, str. 199-203.

Žižek, F., Moja zgodnja gledališka leta, Maribor, 2000. 


\section{VARIOUS STAGINGS OF CANKAR'S WORKS AT THE SLOVENIAN NATIONAL THEATER IN LUUBLJANA AND OTHER SLOVENIAN THEATERS IN THE INTERWAR PERIOD (1918-1941)}

Keywords: scenography, playwriting, Ivan Cankar, interwar art, interwar scenography, expressionism, new realism, avant-garde

\section{Abstract}

Plays by Ivan Cankar unequivocally marked Slovenian theater in the period from 1918 to 1941. In addition to Shakespeare's works, it was Cankar's plays that were most frequently performed on the Slovenian stage. His works especially appealed to directors that were seeking deeper, symbolic meanings of the text, which they tried to present to the audience to the best of their ability. Thus, Cankar's narrative was intensified through directing and acting, whereas the scenery was of secondary importance in most performances. These mostly included painted scenes or backdrops to represent the setting. Only the stagings of Pohujšanje $v$ dolini Šentflorjanski (The Scandal in the St. Florian Valley), Kralj na Betajnovi (The King of Betajnova), Hlapec Jernej in njegova pravica (The Servant Jernej and His Justice), and Lepa Vida (The Beautiful Vida) contained more developed scenography. However, until the 1930s, scenery design for Cankar's plays performed on the professional stage varied between painted backdrops and expressionist sets. It was not until the appearance of the director and scenographer Bojan Stupica that the scenery of these plays reached the boundaries of new realism and modern avant-garde. Until then, an unspoken rule had been in force that the scenery of Cankar's plays should not extend beyond the boundaries of expressionism. This rule was observed even by the avant-garde painter Avgust Černigoj. However, Cankar's plays were staged completely differently in workers' theaters and popular theaters. With new avant-garde staging, they often surpassed the development of theater design in professional theaters, and caught up with contemporary formal ideas in Slovenian and European fine arts. Here, Cankar's works were staged as anti-political propaganda. In order to better express their new ideas, 
these theaters also used new tools, such as projectors and film clips, and experimented with spotlights. The most original among these were the creations by the director Ferdo Delak at the Ljubljana Workers' Theater and the works by Fran Žižek at the District Theater in Ptuj. 